\title{
Mulheres Indígenas, Ensino Superior e Colonialidade de Gênero
}

\section{Indigenous Women, Higher Education and Gender Coloniality}

\section{Elizabeth del Socorro Ruano-Ibarra}

Universidade de Brasília, Brasília, Brasil

Victoria Miranda da Gama

Universidade de Brasília, Brasília, Brasil

\section{RESUMO}

A partir das narrativas de mulheres indígenas no ensino superior, refletimos sobre as suas vivências de múltipla discriminação: pela sua etnia, por serem mulheres, jovens e carentes. Objetivamos salientar as especificidades dos empecilhos enfrentados por essas mulheres para efetivar o direito à educação. A análise toma como referencial as políticas de cotas, a colonialidade de gênero, o racismo institucional e os feminismos. Optamos por uma abordagem mista para a coleta dos dados analisados, que se apoiou na realização de entrevistas, na análise documental e na observação participante. Destacamos a riqueza analítica do pensamento das mulheres indígenas brasileiras, sobretudo, no tocante aos desdobramentos do patriarcado e do racismo institucional enquanto barreiras estruturais à garantia efetiva de direitos.

Palavras-chave: Feminismos, Direito à educação, Etnicidade.

\section{ABSTRACT}

From the narratives of indigenous women in higher education we reflect on their experiences of multiple discrimination, their ethnicity, being women, young and needy. We aim to highlight the specificities of the obstacles faced by these women to realize the right to education. The analysis takes as reference the quotas policies, the gender coloniality, institutional racism and feminisms. We opted for a mixed approach to collect the analyzed data, which was based on interviews, documentary analysis and participant observation. We highlight the analytical richness of Brazilian indigenous women's thinking, especially regarding the unfolding of patriarchy and institutional racism as structural barriers to the effective guarantee of rights.

Keywords: Feminisms, Right to education, Ethnicity. 


\section{INTRODUÇÃO}

Neste trabalho, privilegiamos as narrativas femininas indígenas sobre suas trajetórias no ensino superior, especificamente na Universidade de Brasília (UnB). Buscamos elucidar esse pensamento feminino indígena conferindo-lhe centralidade aos depoimentos de Dirlene Monteiro da etnia Tikun, Samantha Ro'otsitsina de Carvalho Juruna do povo Xavante, Núbia Batista da Silva do povo Tupinambá, Suliete Gervásio e Rayanne França do povo Baré, Geraci Aicuna Mendes e Lindalva Félix Zagur do povo Ticuna. Em 2017, quando realizamos a pesquisa, as interlocutoras indígenas cursavam graduação em biologia, engenharia florestal, nutrição, medicina e duas realizavam mestrado em desenvolvimento sustentável e linguística, respectivamente.

As narrativas analisadas foram obtidas em três espaços de debate acadêmico realizados na UnB: i) mesa intitulada "Mulheres indígenas. Desafio de empoderamento econômico e social" ; ii) minga do Laboratório de "Estudos e Pesquisas em Movimentos Indígenas, Políticas Indigenistas e Indigenismo" (Laepi) titulada "Mulheres Ticuna: gênero e política na Amazônia" e iii) realização de entrevistas abertas. Também analisamos os conteúdos produzidos por mulheres indígenas e divulgados em plataformas de acesso livre: Eliane Lima dos Santos do povo Potiguara; Sônia Bone do povo Guajajara; Célia Nunes Correa do povo Xacriabá; Braulina Aurora do povo Baniwa; Francinara Soares do povo Baré; Samantha Juruna e Rayanne França. A partir da reflexibilidade expressa nessas narrativas, propomos refletir sobre o pensamento feminino indígena no Brasil.

Os povos indígenas brasileiros têm reivindicado o acesso ao ensino superior cientes de que, segundo Mora (2017), as desigualdades étnico-raciais predominam nessas instituições no continente americano. Como desdobramento da histórica exclusão operada mediante os sistemas educativos, os povos indígenas se encontram entre os segmentos sociais com menores índices de escolaridade. Nos termos de Luciano (2011), liderança indígena do povo Baniwa e doutor em antropologia, a conquista do diploma universitário representa para esses povos um instrumento de luta, acima de tudo. Na prática, o direito à educação constitui um meio para a apropriação linguística e, de modo amplo, para conhecer as formas de interlocução da sociedade englobante.

Nessa trilha, questionamos sobre as especificidades da luta indígena pelo direito à educação. Pascoal (2017), a partir da experiência histórica de resistência do povo Krenak, alertou para os diferentes significados da expressão luta indígena. Para ele, essa categoria reflete a consciência histórica das novas gerações e a centralidade dos conhecimentos tradicionais e da ressurgência cultural. Tratar-se-ia de movimentos e dinâmicas sociais para garantir a existência 
coletiva desses povos. Nesse sentido, a categoria luta indígena se refere, principalmente, aos processos internos desses povos.

Alertando para o caráter externo dessas lutas, Ruano e Souza (2017, p. 112) afirmam que o acesso ao ensino superior constitui uma estratégia fundamental. Nas trajetórias de mulheres Ticuna, "a formação acadêmica e a trajetória profissional nos moldes ocidentais constituem diferenciais para legitimar a sua inserção na esfera pública, além de qualificar seu lugar de chefia". Ou seja, os percursos femininos indígenas indicam processos de mudança, apesar dos entraves ao exercício dos direitos das mulheres no âmbito do Estado nacional.

Nesse contexto, questionamos se as narrativas em questão retratam a natureza dos empecilhos enfrentados por mulheres e homens indígenas para acessar e permanecer no ensino superior. Não buscamos hierarquizar, mas apontar com Aura Cumes (2012), pesquisadora Maya-Kaqchikel Guatemalteca, as especificidades dos entraves enfrentados pelas mulheres indígenas e elucidar sobre os desdobramentos do patriarcado no âmbito etnopolítico. Almejamos que, ao repousar o olhar analítico nas narrativas sobre o acesso das mulheres indígenas à universidade, possamos oferecer uma chave diferenciada de compreensão sobre a emancipação feminina.

Tais questionamentos se escoram no debate acadêmico sobre a colonialidade do gênero e suas múltiplas discriminações. Pautado por Maria Lugones (2014), este debate conceitual se refere à intersecção de gênero/classe/raça/sexualidade como construtos centrais do sistema de poder capitalista mundial. Essa perspectiva permite-nos compreender sujeitos históricos, oprimidos mediante exercícios de poder concretos, tais como opressões de gênero intrincadas e explicitadas no "corpo a corpo" das práticas legalistas de racialização em nosso continente (GARGALLO, 2014).

Julieta Paredes (2017), feminista comunitária da Assembleia de Mulheres da Bolívia, defende que o empobrecimento feminino é mais dramático que o masculino, pois as mulheres sofrem perdas causadas pelo colonialismo, patriarcado e racismo. Reconhecer essas injustiças implica em questionar os marcadores dessa subordinação, por serem indígenas e mulheres. Segundo Mora (2017), a tímida presença feminina no ensino superior indica que as desigualdades de gênero também são históricas nessas instituições.

Embora os dados das últimas décadas indiquem crescimento importante, ainda é insuficiente quando ponderado historicamente. Na década de 1970, a porcentagem de mulheres nas universidades brasileiras era de 25\%, ampliando-se, no ano 2000, para 53\% (GUEDES, 2008). Esse aumento pode ser compreendido como reflexo da ação institucionalizada, cujo surgimento pode ser associado ao impacto político dos movimentos e das agendas feministas. Nesse sentido, este artigo visa explanar os percursos de mulheres indígenas na UnB em diálogo com as 
políticas de ação afirmativa e a perspectiva de gênero. Nessas narrativas, o acesso à universidade é percebido como forma de emancipação que incide na constituição e ação dos movimentos indígenas no Brasil. Em tela, o deslocamento das mulheres indígenas das esferas domésticas para os espaços públicos de atuação política, até então majoritariamente masculino. Trata-se, portanto, de refletir sobre um fenômeno bastante atual e que, apenas recentemente, vem sendo objeto de reflexão nas ciências sociais brasileiras.

\section{INDÍGENAS PELO DIREITO AO ENSINO SUPERIOR NA UNB}

O ingresso nas universidades públicas brasileiras é regulado por regras próprias em cada estado da Federação, sendo o vestibular o mecanismo de seleção prioritário. Conforme Barros (2014, p. 157), esse instrumento de escolha dos candidatos às vagas no ensino superior "dissimula o conjunto de fatores que são determinantes para a aprovação". Inspirado na "lógica individualista e competitiva" colocam o sucesso do candidato no processo de admissão "quase exclusivamente como uma responsabilidade individual". Porém, dadas as significativas distâncias sociais, culturais e econômicas, os candidatos competem em condições assimétricas. Isto é, ingressará ao ensino superior quem teve acesso diferenciado à mecanismos de preparação para o vestibular.

Até 2006, a UnB contava com três processos de seleção: o sistema universal (vestibular); o Programa de Avaliação Seriada (PAS), instituído em 1996, e o sistema de cotas que reserva $20 \%$ das vagas para estudantes que se autodeclarem negros, vigente a partir do segundo vestibular de 2004 (WELLER, 2007). De acordo com Belchior (2006, p. 47), o sistema de cotas para estudantes negros se insere na luta e combate ao racismo. Segundo Weller (2007), como resposta à repercussão de uma denúncia de racismo, no Departamento de Antropologia (DAN), a UnB se tornou a primeira universidade federal a implementar o dispositivo.

Em 2004, o convênio celebrado entre a Fundação Nacional do Índio (FUNAI) e a UnB, previu a inclusão de aproximadamente 200 estudantes indígenas, em diferentes áreas do conhecimento, no período de 10 anos. A iniciativa, pioneira no âmbito de uma universidade federal, desvendou vários desafios e evidenciou a urgente necessidade de uma política nacional coesa e bem estruturada (SOUSA, 2009). Cabe destacar que essa determinação não deve ser tomada como ponto de partida da inserção dos indígenas nessa instituição. Conforme Oliveira, Ruano e Sílvia (2017), a trajetória dessa presença é quase tão antiga quanto a própria UnB, fundada no ano de 1962. 
Contudo, as narrativas dos indígenas revelam entraves significativos para a sua permanência na UnB, como se confirma a seguir:

[...] Em muitos casos, as políticas afirmativas não vão além da garantia de mero acesso, caindo no tipo de política "para inglês ver" que, com fins estatísticos, pretende vender uma imagem de inclusão e de tolerância. Os índices numéricos sobre a presença indígena nas universidades dizem pouco sobre o que efetivamente está acontecendo nas salas de aula e nos corredores universitários e dizem menos ainda sobre as condições necessárias para contornar a invisibilidade relegada aos povos indígenas desde os primórdios do processo colonial (CRUZ, 2016, p. 10).

A abertura de vagas para indígenas enquadra-se em uma retórica delimitada ao acesso, importante, porém, insuficiente quando o desafio maior está em garantir a permanência em condições dignas (CRUZ, 2016). Trata-se de criar condições para compreendermos as especificidades da busca pela emancipação da sujeição, exploração e subalternidade no ambiente universitário. É imperioso revisar cursos, repensar espaços de discussão e incrementar currículos. Demonstra-se, ainda, fundamental a abertura epistêmica, desfazendo paradigmas monolíticos e fechados para outras formas de conhecimento. Menendez (2014) reforça essa perspectiva, afirmando que o saber euro e estadunidense-centrado é dominante e relega aos saberes indígenas um lugar hierarquicamente inferior.

Nos debates pela aprovação da chamada Lei das Cotas, os povos indígenas deixaram claro que o acesso democrático deveria levar em consideração aspectos específicos e diferenciados de seus contextos culturais, políticos e demográficos, assim como seus processos próprios de educação (MENENDEZ, 2014). A aprovação, em agosto de 2012, da Lei no 12.711/2012, conhecida como Lei de Cotas, representou apenas "uma gota d'água no oceano da dívida social”. Contudo, reavivou a discussão sobre os desafios para o Ensino Superior no século XXI (CONSELHEIRO, 2006, p. 97). Representou também um avanço para a inclusão social dos indígenas (LUCIANO, 2011), dada a obrigatoriedade da reserva de vagas, atendendo a indicadores de discriminação positiva, como cor, etnia e renda.

A presença indígena na UnB, porém, tem sido marcada por avanços e descontinuidades institucionais, atrelados à sensibilidade e vontade política da reitoria de turno, eleita para períodos de quatro anos. A partir da década de 2000, período em que vigorou o convênio institucional já referido, entre a UnB e a Funai, houve vestibular indígena. No entanto, com o início da gestão universitária do reitor Ivan Marques, 2012-2016, e a finalização do convênio, tal coordenação se tornou tristemente célebre pela suspensão deste vestibular específico.

A representação indígena afirma ter requerido formalmente pela continuidade do vesti- 
bular indígena, sem sucesso.

Quando nós temos algo para pedir, a gente faz um documento através da associação e protocola lá na reitora [...]. Na gestão anterior [Ivan Marques de Toledo Camargo], a gente estava lá, pressionando, mas não deram atenção para nós. Acho que jogavam nossas reivindicações na gaveta (Dirlene Monteiro, Brasília, 26 abr. 2017).

A interrupção do vestibular específico remete ao debate sobre racismo institucional, muitas vezes velado, na gestão e definição desse processo de seleção. Tal compreensão parece confirmar-se no fato da sua reabertura em 2016, com o início da gestão da reitora Márcia Abrahão (2016-2020).

Com a nova gestão [Márcia Abrahão], a gente continuou a buscar de novo o vestibular [específico]. Parece que agora andou um pouco [...]. Vai sair o vestibular neste ano, em novembro [2017]. São esperados no mínimo 38 e no máximo 40 alunos indígenas novos. [...] Ano que vem, vão entrar mais estudantes indígenas. Serão duas entradas [dois vestibulares por ano]. O outro vai ser em 2018 (Dirlene Monteiro, Brasília, 26 abr. 2017).

O vestibular específico anunciou, para o $1^{\circ}$ e $2^{\circ}$ semestre de 2018, 72 vagas em 13 programas: Administração, Ciência Política, Ciências Sociais, Comunicação Organizacional, Enfermagem, Engenharia Florestal, Fisioterapia, Gestão Ambiental, Jornalismo, Medicina, Nutrição, Psicologia, Saúde Coletiva, Serviço Social, Direito, Gestão do Agronegócio e Licenciatura em Ciências Naturais, os três últimos em horários diurno e noturno.

Os indígenas receiam que esses avanços pontuais coloquem em risco o dinamismo da sua mobilização por demandas mais amplas e por mudanças de longo prazo. "Quando a gente consegue alguma coisa, geralmente dá uma estabilizada, fica acomodado. Não pode, porque se fica acomodado, as coisas desandam”, nas palavras de Suliete Gervásio. (Brasília, 26 abr. 2017). Embora a reabertura do vestibular específico indique um contexto institucional favorável, também revela seu caráter provisório, evidente na negativa de alguns cursos - biologia e odontologia - em ofertar vagas para candidatos indígenas.

A representante discente defende a importância da sua "luta para que a universidade tenha políticas específicas para indígenas" (Suliete Gervásio, Maloca UnB, 26 abr. 2017). A institucionalização dessas políticas, na compreensão dos estudantes indígenas, permitiria contornar os entraves e as descontinuidades institucionais. Pondera-se que a burocratização disfarça preconceitos, tornando-se um obstáculo eficaz para barrar seu ingresso. As justificativas dos gestores das unidades acadêmicas, que negam a abertura de vagas para os indígenas, por vezes, 
naturalizam e ocultam desigualdades estruturais no acesso ao ensino superior no Brasil.

Como já colocado, ditas desigualdades apresentam marcadores de gênero, etnia e racialidade. Nessa trilha, a justaposição dessas dimensões ganha maior complexidade nas trajetórias das mulheres indígenas que almejam ingressar ao ensino superior. Não se trata apenas de superar os obstáculos já referidos nessas instituições, antes disso elas precisam desvencilhar entraves ao interior de suas famílias e de seus povos. A seguir, buscamos compreender essas dinâmicas, mediante a aproximação que nos permitem as referidas narrativas.

\section{"EU VOU ESTUDAR!": MULHERES INDÍGENAS DESAFIANDO 0 PATRIARCADO}

Neste item, enfatizamos nas narrativas femininas e nos movimentos de mulheres indígenas, a centralidade do direito à educação. Inferimos tratar-se de uma estratégia eficaz de tensionamento do poder masculino e, simultaneamente, de promoção do envolvimento feminino na política, no âmbito público. O que levou à subordinação feminina, quando em diversos mitos amazônicos , a mulher é referenciada como protagonista da criação e transformação do universo? Tal indagação é demarcada na mitologia indígena do povo Sateré-Mawe, onde as mulheres são referidas como protagonistas na criação do universo, em contraposição à condição feminina subordinada nas relações contemporâneas. Essa compreensão ganhou seus contornos em 2018, durante o Acampamento Terra Livre, quando as mulheres indígenas reivindicaram a inclusão da pauta feminina na agenda das futuras edições do ATL.

Até o início dos anos 2000, a liderança dos movimentos indígenas no Brasil se caracterizou pela conformação notadamente masculina. Todavia, as mulheres indígenas não ficaram à margem nas relações etnopolíticas, seja com outras etnias ou com não indígenas. Mesmo que historicamente não frequentassem espaços públicos e de fato sua participação fosse limitada, não se afastaram das lutas dos seus povos. Libalva Félix Zagur, indígena Ticuna, lembrou que participa do movimento indígena desde os três anos de idade. Gostava de escutar e observar as reuniões, mesmo que a sua presença não fosse aceita formalmente. "Naquele tempo só os homens que representavam. [...] eu nunca fui aceita nas organizações. Só gostava de participar para ouvir o que era que os caciques tratavam. [...] Isso para mim desenvolveu muito [...]" (Brasília, 22 set. 2017).

Nesse sentido, revelou que somente o fato de acompanhar as discussões, acrescentou aprendizados: 
[...] depois eu fui vendo. [...] Eu pensei em criar uma organização das mulheres indígenas. [Naquele tempo me imaginei] como presidente, como liderança de alguma organização de mulheres. Que seja um dia, quem sabe, chegar ali também para ajudar essas mulheres, para poder compartilhar alguma coisa.

Gabriela Pinheiro do povo Kariri-Xocó, estudante de antropologia na Universidade de Brasília, nos brinda com o seguinte enunciado em que destaca a importância ancestral das mulheres e a influência feminina nas iniciativas atuais promovidas pelas mulheres indígenas:

Somos uma geração privilegiada porque tivemos mulheres para nos inspirar e espelhar. Se não fosse a atuação delas tocando tudo isso [...]. Não estaríamos como estamos nos posicionando, aplicando o conhecimento de nossas avós. Afirmando o compromisso que temos com o coletivo. Não queremos fazer nada separado [...]. Esse exemplo me faz acreditar em um futuro mais tranquilo para as mulheres indígenas. (Gabriela Pinheiro, Brasília, 15 abr. 2019)

Do mesmo modo, Eliane dos Santos, do povo Potiguara, mediante sua escrita, promove o universo feminino e os saberes imemoriais promovidos pelas mulheres indígenas para denunciar a colonização e a expropriação. No poema "Segredo das Mulheres", dedicado à Severina, sua tia e anciã guerreira, exalta o prestígio e a influência das mulheres enquanto pilares fundamentais da sabedoria ancestral. No livro "Metade cara, metade máscara" (Santos, 2004), demarca sua militância em defesa das etnias brasileiras e destaca as contribuições de outras mulheres indígenas. Segundo Peres (2017, p. 130), a obra de Eliane Santos confirma "a mulher como sujeito histórico, capaz de falar, capaz de autobiografar-se como sujeito, protagonista e referência".

Os embates para tornar-se liderança indígena são múltiplos. Nesse contexto, as ações políticas lideradas por mulheres eram raridade e nem sempre alcançavam visibilidade.

[...] antigamente tinha a esposa do Seu Pedro Inácio. A dona Gracila, depois que ela morreu enfraqueceu o movimento feminino. Eu acho que foi mais por falta de incentivo. [...] Se você esperar não vai ter apoio. As mulheres têm que se unir mesmo, e seguir adiante (Geraci Mendes, Brasília, 22 set. 2017).

Francinara Soares, conhecida como Nara Baré, do povo Baré, relatou que as lutas para consolidar a participação feminina na cena pública "vem de geração em geração. Passando de avó para mãe e de mãe para filha e agora das filhas para os netos”, isso porque Rosa, sua tia-avó, foi a primeira mulher eleita vereadora em São Gabriel da Cachoeira (Amazônia Real, 2017). Nara Baré se desempenhou inicialmente como tesoureira da Coordenação das Organizações Indígenas da Amazônia Brasileira (Coiab), maior organização indígena do Brasil, fundada há 28 
anos. Posteriormente, foi a primeira mulher eleita para assumir a coordenação geral da Coiab, no período 2017-2021.

Nara Baré cursou administração na Universidade Estadual do Amazonas (UEA), onde ingressou no Movimento dos Estudantes Indígenas do Amazonas (Meiam). Segundo afirmou, "nós mulheres indígenas nunca tivemos a voz realmente. Nós tínhamos porta-vozes, que eram nossos irmãos, nossos pais, nossos maridos" (Amazônia Real, 22 set. 2017). A análise das narrativas sobre suas trajetórias permite compreender a complexidade das dinâmicas que permitiram a conquista da voz e dos espaços às mulheres indígenas do Brasil.

Nos primeiros momentos, agruparam-se em associações específicas ou
de gerenciamento feminino (associações de artesãs em São Gabriel da
Cachoeira), organizadas por interesses políticos e econômicos. Por meio dessas
associações, lidavam com problemas comuns aos homens (demandas por terra,
geração de renda, educação, saúde etc.), mas a partir da perspectiva indígena
feminina. Somente anos depois, as mulheres indígenas formularam demandas
específicas ao gênero feminino, como cuidados com a saúde reprodutiva e
criação dos/as filhos/as, combate à violência contra mulheres (em decorrência
do alcoolismo), reivindicação por maior participação feminina nos espaços
públicos indígenas e indigenistas, maior oportunidade de capacitação das
mulheres indígenas, entre outras demandas (MATOS, 2012 p. 148).

A prioridade das pautas associadas à saúde reprodutiva e cuidados da prole, além de maior oportunidade de capacitação, revelam a preponderância do âmbito doméstico na ação feminina indígena. Samantha Ro'otsitsina Juruna, da etnia Xavante, em entrevista fornecida durante o $15^{\circ}$ Acampamento Terra Livre (ATL), afirmou que "tem povos onde as mulheres casam cedo, com 15 ou 16 anos. E nem todas permanecem na escola depois de se casarem. Não que seja proibido estudar, mas porque elas não conseguem conciliar o estudo com a casa e a família" (ROSSI, 2019, n. p.).

Conforme Ruano e Sousa (2017), a liderança feminina no âmbito dos indígenas do Brasil, se ancorou em reivindicações nas áreas de educação, saúde, segurança alimentar, benefícios sociais, moradia e "políticas femininas", no de programas governamentais voltados para esses povos. A partir desse contexto, setorialmente demarcado, construíram-se espaços de participação feminina. Sônia Bone, conhecida como Sônia Guajajara, primeira indígena brasileira a formar uma candidatura presidencial em 2018, relembrou este momento, assim:

Foi nesse período [início da década de 2000] que eu comecei a participar muito da luta das mulheres. Foi quando eu conheci a Valéria Kaxiuana, a Rosemary Arapaço, a Michelina Tukano. Elas todas eram muito focadas na questão da luta das mulheres. Eu me aproximei delas e rapidamente já estava muito envolvida, organizando encontros de mulheres. Eu acabei ficando mais 
um mandato na [coordenação das organizações e articulações dos povos indígenas do Maranhão] COAPIMA, até 2009, e aí durante esse segundo mandato eu me aproximei muito de todas as lutas, das mulheres, das questões ambientais, das questões políticas (COHN; KADIWEL, 2018, p. 16).

A demarcação de espaços femininos é colocada por Libalva Zagur como forma de subverter a estrutura hierarquizada e masculina: "a gente tinha um projeto com mulheres. Eu, minha irmã e minha tia criamos esse projeto. Trabalhávamos com mães solteiras", porém, "os homens da aldeia, não aceitavam por sermos mulheres". O depoimento se refere à idealização de um projeto de artesanato que, finalmente, permitiu-lhe legitimidade como líder, "o cacique pediu para voltar à aldeia. Ele disse assim: Libalva, eu quero que você fique como representante. Já que você estudou um pouco, quero que você forme uma organização" (Brasília, 22 set. 2017). Essa aprovação tardia, pela liderança masculina, da importância da iniciativa feminina, confirma o tensionamento das relações de gênero, no sentido de ampliar o horizonte compreensivo desses povos.

Diziam: a mulher não pode sair, a mulher tem que estar em casa. A mulher tem que estar cuidando de filho, a mulher tem que fazer comida para o homem. $\mathrm{O}$ homem tem que sair para resolver alguma coisa. É por isso que as mulheres Ticuna preservam. Só que eu vejo assim: não é por aí. [...] depois eu fui vendo outras mulheres participando, representando organizações de mulheres. Quando eu completei vinte e dois anos saí da minha aldeia (Libalva Zagur, Brasília, 22 set. 2017).

Nesses enunciados, a centralidade masculina na posição de líderes e responsáveis pela condução dos movimentos indígenas, incidia no lugar periférico das mulheres. Ainda assim, a oportunidade de circular nessas plenárias e vivenciar experiências coletivas permitiram ampliar e aprofundar suas perspectivas políticas e sociais, o que ensejou a motivação e o ativismo feminino. Na avaliação do cenário atual, mostra-se otimista porque "hoje em dia tem muitas meninas, muitas, mesmo, que saem da comunidade para estudar. Elas hoje em dia têm mais cabeça [...] quando você as convoca para uma reunião.” (Libalva Zagur, Brasília, 22 set. 2017).

[...] eu enfrentava o meu pai. Ele dizia que mulher era para ficar em casa. Como eu tinha filhas, ele sempre dizia assim: 'E quem vai cuidar das suas filhas, já que você separou?' Eu disse: 'Ué, elas ficam aí na casa da minha irmã. Eu vou trabalhar'. [...] para meu pai foi um desafio grande. Mislene [liderança Ticuna, Coordenadora-Geral da Funai no Alto Solimões] e minha outra irmã, sempre me apoiaram. Diziam: 'Vai, se é isso que tu queres, vai. Algum dia ele vai ver que é pelo nosso bem' (Geraci Aicuna Mendes, Brasília, 22 set. 2017).

Apreende-se dessa narrativa que as relações de gênero são pautadas pela hierarquia so- 
cial e pela divisão sexual do trabalho. Às mulheres caberiam as tarefas de cuidado das coletividades étnicas tanto no âmbito doméstico (lar ou aldeia) como no espaço público (no caso nas mobilizações fora dos territórios indígenas). Nesse contexto, a procura dessas mulheres por participação política e intercâmbio com outras realidades representa tensionamentos e deslocamentos de poder. Em tal perspectiva, tem-se que as masculinidades demarcam e condicionam as possibilidades políticas e sociais dos povos indígenas. Para Samantha Juruna:

Nós mulheres não somos parte do povo, nós somos o povo [...]. Então, violando uma menina, violando uma mulher, você está violando o povo. Ou seja, qualquer pessoa que faça mal a mim, que machuque fisicamente ou verbalmente a mim, ou a qualquer mulher, ele está fazendo algo contra o meu povo e a minha cultura (ROSSI, 2019, n. p.).

Habitualmente compreendidas como inerentes à natureza masculina e intrinsecamente entroncadas nas relações de poder e de produção, as masculinidades incidem determinando funções sociais a partir do atributo binário, homem/mulher. Conforme José Luís García e Emma Zapata (2008), as masculinidades se sustentam na associação entre poder, autoridade e hierarquia. Nesse sentido, compreendemos a complexidade da subordinação explícita na seguinte narrativa:

Existem muitas comunidades que para ser liderança tem que ser cacique. Tem
que ser filho de cacique. [...] Hoje para ser cacique é mediante eleição. Têm
pessoas que se mudam da aldeia porque uma mulher assumiu a liderança,
porque ganhou a eleição. [...] Parte da comunidade muda, vai procurar outro
território porque dizem que não querem ser mandados por mulher (Geraci
Mendes, Brasília, 22 set. 2017).

Essa narrativa permite equacionar que a presença feminina indígena na arena pública tensiona a supremacia masculina na liderança. Samantha Juruna, em entrevista concedida ao programa Mulheres da ONU, frisou ditos tensionamentos nas estruturas de poder étnico e sua compreensão sobre as práticas que negam o reconhecimento político às mulheres indígenas:

Soy una mujer joven Xavante. [...] Pero hay temas culturales aún más fuertes. No soy casada y no tengo hijos. Algunos hombres de mi pueblo no comprenden estos factores de una mujer contemporánea. No los culpo. Después de 75 años de contacto con la sociedad no-indígena, no tenemos registro de una mujer Xavante capaz de discutir y apoyar políticamente a los pueblos indígenas en el ejercicio de los derechos indígenas. Esto es una historia política y cultural reciente de mi pueblo.

Actualmente estoy pasando por una fase de aprendizaje colectivo, en el que como una mujer joven Xavante experimento espacios políticos locales, 
utilizados hasta ahora solo por los hombres Xavante. Algunos de estos hombres están aprovechando la oportunidad de aprender conmigo las experiencias que he adquirido en el contexto del movimiento indígena nacional. En otros pueblos indígenas en Brasil, las mujeres ya tienen espacios de participación y diversas mujeres ya están contribuyendo a la discusión del movimiento indígena. Pero en el pueblo Xavante, la resistencia cultural al hecho de tener a una mujer en la posición de toma de decisión aún es un desafío para ser superado, tanto por mujeres como por hombres (MI PADRE ME DIJO..., 2014, n. p.).

Essa crítica às justificativas culturais que limitam o exercício político feminino não almeja enfraquecer a representação masculina. Ao contrário, defende-se o compartilhamento da cena política entorno da defesa dos direitos étnicos. Sendo assim, o ensino superior aparece como possibilidade de autonomia, pois amplia as possibilidades de mobilidade e incidência em outras esferas da vida coletiva. A seguinte narrativa sinaliza a busca por emancipação ancorada no direito à educação:

Eu queria estudar. Minha família apoiou meu marido que não me deixava ir estudar. [...]Então eu disse: 'Você vai embora e eu vou ficar morando com minha mãe'. E minha mãe falou assim: 'não. Você vai ficar com o seu marido'. E eu: 'não. Eu vou estudar!' [...] Eu tinha acabado de separar do pai da minha filha. [...] Ele foi embora, eu fiquei na casa da minha irmã, porque minha mãe não me aceitava (Geraci Aicuna Mendes, Brasília, 22 set. 2017).

De acordo com Francesca Gargallo (2014), as mulheres podem ser incisivas nas práticas de discriminação e vulneração de direitos próprios do patriarcado. A sororidade se coloca como desafio para a superação da supremacia masculina, evidente no controle entre gerações como no trecho acima. A mãe castigará os anseios da filha executando a vontade dos homens da família ou limitará a mobilidade das filhas e noras para privilegiar a liberdade dos homens. Tais fenômenos enfatizam a carente autodeterminação das mulheres entre elas e com relação às suas famílias. É nesse contexto que Julieta Paredes (2017) entende os feminismos enquanto conceito que traduz essas lutas femininas em diálogo com outras para viver uma vida boa.

A partir da narrativa de Geraci Mendes (Brasília, 22 set. 2017), descobrimos uma trajetória emancipadora construída mediante sua inserção no ensino superior. “[...] eu passei no vestibular e minha mãe já estava meio que entendendo [meu anseio por ingressar na universidade]. Depois eu terminei os estudos, fui trabalhar na prefeitura e daí desenvolvemos esse projeto [criação da Associação de Mulheres]". Essa afirmativa coincide com narrativas de outras mulheres indígenas que destacam a importância da efetivação do direito à educação nas dinâmicas de emancipação feminina. Por isso, afirmar-se enquanto sujeito de direitos é uma demanda feminina que, como no caso de Samantha Juruna, é encorajada por lideranças masculinas. 
[...] Quando eu tinha 14 anos eu queria namorar, mas meu pai não deixou. Ele disse que eu deveria estudar, trabalhar, ser independente. Ele disse 'não quero que você dependa de um homem ou de qualquer pessoa para se vestir, se alimentar. Eu quero a sua independência, pessoal e profissional' (ROSSI, 2019, n. p.).

Ocupando espaços universitários, políticos, sociais e econômicos, essas mulheres evocam a luta de outras mulheres que a precederam. Deste modo, valorizam e reconhecem a importância dos conhecimentos apropriados, desde suas ancestrais, aos espaços coletivos ainda majoritariamente masculinos. As trajetórias de suas avós e mães, junto às de representantes com importante notoriedade na política interétnica, como Joenia Batista de Carvalho , do povo Wapichana e Sônia Guajajara, contribuem para encorajar os ativismos femininos atuais. Segundo Samantha Juruna, os conhecimentos, portanto, vinculam-se.

Talvez há 100, 500 anos, quando não existia o trabalho assalariado, o estudo fora da aldeia, falar sobre isso seria estranho até. Mas hoje, nós mulheres precisamos ter oportunidades iguais no processo educacional, no conhecimento. Precisamos ter o direito de escolha. Eu tenho 34 anos, não sou casada e não tenho filhos, mas eu tive escolha. Tem meninas que não tem (ROSSI, 2019, n. p.).

O destaque para o direito à educação, especificamente o ingresso ao ensino superior, como oportunidade de empoderamento feminino também é frisado por Rayanne França, do povo Baré, em entrevista ao programa Mulheres da ONU.

Dejé mi hogar y mi comunidad a los 17 años. Mi familia se había visto afectada por las frecuentes amenazas de muerte que sufrimos cuando mi padre denunció hechos de corrupción. Al presentarse la oportunidad de dar el examen de ingreso a la universidad, insistieron en que no la desaprovechara. Para ellos, mi partida significaba ponerme a salvo del peligro. Para mí, se trataba de un viaje de ida hacia la independencia y el empoderamiento (MI PUNTO DE VISTA..., 2017, n. p.).

Nessa trajetória, é colocado em relevo que algumas pautas ligadas aos direitos das mulheres, especificamente no que tange à sexualidade e reprodução, ainda não constituem temáticas amplamente discutidas em todas as esferas da vida universitária e da sociedade brasileira como um todo. A questão evidente nessa narrativa é que conhecer as opressões é determinante para combatê-las.

[...] Soy estudiante de enfermería, y la primera vez que oí hablar de los derechos sexuales y reproductivos de las mujeres fue en 2014, cuando asistí a una reunión regional de mujeres indígenas en Nicaragua. [...] En una comunidad indígena, si tienes tu primer período a los 10 años, a esa edad serás 
considerada mujer. Eres "joven" en tanto tu comunidad considere que lo eres; aunque esto no se ajuste a la definición de las organizaciones internacionales (MI PUNTO DE VISTA..., 2017, n. p.).

Porém, a ruptura com a subordinação patriarcal encontra barreiras que refletem as assimetrias do padrão de poder que subalterniza mulheres e homens indígenas. Segundo Libalva Zagur (Brasília, 22 set. 2017), na sua aldeia se questionava “o que eu vou fazer aqui? Preciso ser alguém. Por isso, [...] fui embora para Manaus e lá terminei meu ensino médio. Na época não sabia falar bem português, ainda não sei”. Na interação constatamos a fluência idiomática característica de quem usa uma segunda língua. Assim, o receio de inaptidão perante as barreiras linguísticas opera como interiorização da subordinação.

Conforme expressou Suliete Gervásio (Brasília, 26 abr. 2017) "a gente é obrigada a se adaptar [...] individual não consegue [permanecer na universidade e obter o diploma], tem que ser no coletivo, mediante uma associação". Desde a década de 1970, se expressou um significativo crescimento de organizações indígenas no continente americano (BATALHA, 1981). No Brasil, a adoção desse modelo "alienígena" não sempre compatível com as tradições e culturas indígenas, pode ser estratégico para promover ações politicamente, perante à retração estatal e ao desrespeito aos direitos indígenas (LUCIANO, 2011).

No que tange à Associação dos Acadêmicos Indígenas da Universidade de Brasília (AAIUnB), presidida no período 2016-2018 por Braulina Aurora, do povo Baniwa, graduanda em Antropologia, registra-se uma série de avanços nas reivindicações que buscavam pelo reconhecimento do saber indígena na instituição universitária.

Nesses 13 anos de presença, temos conquistado, além do espaço, a oportunidade de poder falar da nossa realidade e de como é ser indígena neste século, em que se usa tecnologia não indígena. Além disso, representa a consciência de não deixar de lado nossas tecnologias, pois os dois conhecimentos só vêm somar à luta pelos nossos direitos (INDÍGENAS..., 2017, n. p.).

Segundo Núbia da Silva, indígena Tupinambá, doutoranda em Linguística na UnB, o acesso ao ensino superior é um anseio da coletividade, embora o deslocamento da aldeia para a universidade constitua uma empreitada individual.

Nasci na cidade, minha mãe saiu da aldeia com 15 anos. [...]. Quando consegui passar no vestibular em Pedagogia eu descobri que a função do professor é ser, é ampliar esse universo, alimentar os sonhos e dar esperança. [...] Tenho que voltar para meu povo tudo o que eu aprendi. Na aldeia tentei junto com meus parentes, organizar um grupo de professores na função da escolarização. Depois estava envolvida com o movimento indígena da educação e com o movimento de alfabetização de jovens e adultos. Também estava coordenando 
o Encontro Estadual de Educação Escolar Indígena (Núbia Batista da Silva, Brasília, 27 mar. 2018).

Célia Nunes Correa, do povo Xakriabá, na conferência titulada "Mulheres Indígenas, resistência e protagonismo" (CORREA, 2018), defendeu que as/os discentes indígenas precisam se legitimar tanto na universidade quanto nos territórios tradicionais mediante instâncias de legitimação mútua.

Em 2010, quando eu estava cursando Ciências Sociais, com habilitação em Sociologia, fui convidada para assumir o papel de professora do meu povo. Para mim foi um convite muito importante. Porque no contexto acadêmico o mais importante é ser professor na universidade. Mas para nós, professores indígenas não são aqueles que dominam somente a escrita, mas aqueles que conhecem a cultura do seu povo em profundidade (Brasília, 27 mar. 2018).

Dessa narrativa, infere-se uma ruptura com a hierarquia de saberes própria do conhecimento de matriz ocidental. Nesse sentido, reconhece-se que os saberes de ambos universos perpassam trajetórias tornando-as qualificadas para as demandas dos povos. A partir desse lugar, enquanto professora indígena e mestre pela UnB, Célia se coloca como mediadora entre o mundo Xakriabá e o acadêmico.

Núbia da Silva destaca, ainda, o caráter reflexivo sobre seus percursos, seus povos de origem e as especificidades da sociedade envolvente.

Fiz o mestrado na UnB, [e analisei] a nossa presença na universidade perguntando como é que nós estamos? Estudei a nossa trajetória. Como cada um chegou aqui. Questionei ainda como vocês que não são indígenas nos veem e nos reportam (Núbia Batista da Silva, Brasília, 27 mar. 2018).

Das narrativas aqui apresentadas, compreende-se que a inserção das mulheres indígenas na universidade oportuniza a apropriação de capital simbólico e relacional a partir dos quais defendem seus direitos coletivos. De acordo com Ruano e Sousa (2017), as mulheres lideranças indígenas brasileiras têm como traços comuns o percurso escolar, o bilinguismo e uma profissão. Nessas trajetórias, esses aspectos mostraram-se relevantes para compreender a sociedade nacional e o lugar das mulheres nos processos de mobilização indígena atual.

Tais trajetórias também permitem pensar a universidade enquanto espaço de encontro feminino e realocação da representação masculina indígena. Segundo Nara Baré, "hoje é diferente, porque estamos junto com eles. Hoje a nossa voz vai muito mais longe" (Amazônia Real, 2017). A partir dessa reconfiguração, compartilham experiências, exprimindo seus anseios, culminando em ações ativas e relativamente autônomas. Significa, portanto, que a mudança 
inicia em suas próprias trajetórias, nas aspirações por reconhecimento de suas culturas, na cristalização de modos de resistência e na preservação do legado pela efetivação de seus direitos coletivos: "hoje a voz de Mislene [Mendes, liderança Ticuna] é ouvida. Então a gente se inspira muito nela. É como mulher mesmo que a gente a cita" (Geraci Mendes, Brasília, 22 set. 2017).

\section{VULNERABILIDADE INDÍGENA NA UNIVERSIDADE}

$\mathrm{Na}$ introdução, tratamos brevemente da vulnerabilidade econômica das mulheres indígenas, na perspectiva do empobrecimento feminino apontado por Julieta Paredes (2017). Destacamos que, ao longo do tempo, as mulheres se tornaram mais pobres em comparação aos homens como denunciado pioneiramente no conceito de 'feminização da pobreza' acunhado por Diane Pearce (1978). Nesta seção, no entanto, buscamos evidenciar a complexidade da vulnerabilidade indígena, frisando as restrições financeiras, os estereótipos e preconceitos, bem como as dimensões da colonialidade de gênero direcionadas aos corpos e suas emoções.

A escolha da UnB é atravessada por múltiplos fatores. Dentre eles, o prestígio da instituição, o vestibular específico e o fato de Brasília ser a sede do poder estatal. Braulina Aurora, presidenta da AAIUnB no período de 2016-2018, relata que "tomou gosto pela educação e escolheu a capital porque buscava o desafio de acompanhar as questões sociais perto do centro do poder. O curso possibilitou lutar por temas como educação, território e saúde”. Porém, "achou as pessoas frias [...] Não dá para esquecer que o Galdino foi queimado na Asa Sul. Andamos sempre em grupo e geralmente com meninos. Não me arrisco a andar sozinha" (FAGUNDES, 2018).

Refletir sobre a vulnerabilidade indígena no contexto urbano leva a ponderar também que o deslocamento para a universidade, que em alguns casos inclui a família inteira, desdobra-se em custos financeiros inexistentes nas aldeias. Braulina Aurora, "desdobra-se entre as exigências acadêmicas, a militância e o cuidado dos filhos, de 12 e 6 anos, que se deslocaram do Amazonas para acompanhá-la” (FAGUNDES, 2018). Similar situação é vivenciada por Núbia Batista da Silva, quem relatou "minha família veio comigo, meu esposo, minha filha e minha mãe".

O deslocamento individual ou com o grupo familiar da aldeia para a cidade suscita carências culturais e descompensação emocional decorrente do distanciamento afetivo de seus territórios. A adaptação à cidade e a vida universitária é referida no seguinte relato:

[...] emocionalmente falando, o ambiente em si, ele mexe muito com a gente. 
Acordar e não ver o mar, para mim era dolorido demais. Dolorido de eu chorar, e não conseguir me levantar [...]. O ambiente em si, ele mexe muito e faz a gente sofrer. [...] mudar de ambiente é um sofrimento. É um aprendizado e um sofrimento (Núbia Batista da Silva, Brasília, 27 mar. 2018).

Conforme a narrativa de Núbia da Silva, a renda familiar exerce importância indiscutível nos entraves que inviabilizam o acesso dos povos indígenas à educação básica ou constringem sua permanência, ao carecerem das condições mínimas.

Estudar sem livro, com um toquinho de lápis. Chegar a época de estudar e não ter um lápis. Não ter o livro que a escola vendia, na época era vendido. Meu pai não podia comprar. Essa dificuldade eu sei que passei por vir de uma origem humilde. Porque a vida não é fácil, nunca foi (Brasília, 27 mar. 2018).

Segundo seu relato, ao ingressar na universidade as dificuldades financeiras tornaram-se críticas. Precisava de renda para bancar os custos de morar em uma cidade além de precisar apoiar economicamente à família que ficou na aldeia, principalmente composta por idosos e crianças.

[...] teve vezes que eu só tinha duas passagens, para chegar na universidade $\mathrm{e}$ voltar para casa. Mas eu pego quatro conduções, às vezes cinco. [....] E ficava sem dinheiro para comer o dia todo. Foi assim no comecinho, e eu não desisti [...]. Eu vinha na universidade, bebia água, porque não tinha um centavo para comer. O cartãozinho do transporte [subsídio governamental para estudantes do Distrito Federal] demorou [em ser liberado]. Para conseguir o RU [subsídio de alimentação no restaurante universitário] demorou aproximadamente um ano. Tudo isso é muito sofrimento para gente (Núbia Batista da Silva, Brasília, 27 mar. 2018).

Essa vivência de fome e de mobilidade urbana obstaculizada, afeta negativamente o estudante e o aproveitamento escolar. Neste caso, ambas limitações foram contornadas mediante subsídios públicos do nível distrital e federal. No entanto, a continuidade dessas políticas fica atrelada ao programa promovido pelo governante em curso. Em 2019, o governo distrital anunciou o cancelamento do subsídio de transporte conhecido como Passe Estudantil, recuando da decisão após a mobilização dos estudantes.

O subsídio de alimentação no restaurante universitário foi reestruturado em 2016, após o impeachment da presidenta Dilma Roussef, e a sanção da Emenda Constitucional $\mathrm{n}^{\mathrm{o}} 55$, em 2017. Essa reforma que prevê duas décadas sem investimento público em educação, colocou em xeque o programa federal de bolsas e implicou em consequências imediatas para o estudantado indígena: "estou sem bolsa, todos nós que entramos agora [2018] [...]. Se não sair bolsa, 
eu vou ter que trancar o doutorado. Eu estou certinha disso, precisarei trabalhar" (Núbia Batista da Silva, Brasília, 27 mar. 2018).

A partir da década de 2000, o ingresso ao ensino superior brasileiro foi ampliado para famílias de menor renda, dinâmica que exigiu a criação de programas de apoio à permanência, especificamente bolsas e auxílios de custo. Essas políticas reconheceram a pluralidade e a especificidade socioeconômica dos povos e grupos identitários de origem do corpo discente. Porém, ao nortear-se pela renda familiar como critério de priorização para a outorga desses apoios, reproduziram o caráter excludente do ensino universitário. Segundo os estudantes indígenas, não conseguem o auxílio moradia ou o tiveram suspenso porque o critério de baixa renda da Diretoria de Desenvolvimento Social (DDS) não considera as diferenças culturais desses povos (OLIVEIRA et. al., 2017).

A vulnerabilidade socioeconômica empurra-as para situações que constituem o cotidiano de outros grupos sociais urbanos criminalizados. Segundo Libalva Félix Zagur, diante da urgência de encontrar moradia, se viu compelida a juntar-se a "uma ocupação de sem-teto em um escritório desativado do metrô, perto do zoológico, a quarenta minutos de ônibus da UnB". Buscando contornar a adversidade e viabilizar a permanência na universidade, "o imóvel abandonado" se transformou em "sitiozinho confortável" decorado, "com artesanatos de várias etnias" e compartilhado com outras indígenas sem condições de pagar aluguel (SCARPIN, 2013).

As agressões simbólicas cotidianas nas salas de aula do ensino superior configuram um quadro de vulnerabilidade que raramente são enunciadas. Analisá-las é um desafio inicial para combatê-las. Para as mulheres indígenas, é um direito desnaturalizar essas violências.

Frequentemente me perguntam, nesse território acadêmico [que é duro, frio e
desbotado], como me sinto em ser a primeira indígena Xacriabá a chegar no
mestrado? Eu não sei exatamente como responder. Toda vez que me fazem
essa pergunta eu me sinto muito violentada. [...] para mim o mais importante
não é ser a primeira, mas não aceitar ser a única. Ser a primeira me dá a
responsabilidade de questionar, por que depois de tantos séculos eu sou a
primeira, sendo que somos 11.000 indígenas Xacriabá? (Célia Nunes Correa,
Brasília, 27 mar. 2018).

A proficiência linguística, em português e inglês, é um ideal imposto, desconhecendo as especificidades do corpo discente. Para Santos (2010), ensinar português para indígenas universitários implica evocar as vozes abafadas e silenciadas mediante violentos processos socioculturais de imposição linguística. Braulina Aurora e Libalva Zagur, graduandas Ticuna, relataram ter iniciado o aprendizado da língua portuguesa aos 18 e 22 anos de idade, respectivamente. Nesse sentido, a proficiência linguística não diz apenas sobre a competência comunicativa, pois 
se desdobra em inibições, constrangimentos e em menções ruins.

Tal habilidade linguística, calcada na colonialidade (LUGONES, 2014), revela a sujeição epistêmica monocultural, também presente nos estigmas e estereótipos agenciados em sala de aula.

Teve professor de Medicina que não nos queria lá. [...] Ele falava que tinha aluno indígena que não sabia o que era $\mathrm{H}_{2} \mathrm{O}$. Ele dizia: 'ó, não faz trabalho com aluno indígena, porque você sabe que sua nota vai ser menor'. Os indígenas chorávamos na aula dele. Ficava falando mal de índio no blog dele [...] (Hauni Monteiro, Maloca-UnB, 26 abr. 2017).

Cientes dos dispositivos de poder que os constringem, denunciaram o racismo institucional e demandou a intervenção do Ministério Público para garantir, especificamente, tratamento digno e de modo amplo, garantia dos direitos constitucionais enquanto sujeitos étnicos. Com a mediação do Ministério Público, o docente foi suspenso da sua função e apresentou desculpas argumentando que "não houve má intenção, que também tinha sangue indígena". Por não constituírem uma raridade, as atitudes retrógradas do professorado atualizam a colonialidade nas relações entre docentes e discentes indígenas. A narrativa de Rayanne França, indígena Baré, também reverbera a pretensa superioridade racial e epistêmica.

Yo era uno de los 35 estudiantes indígenas entre 22.000 matriculados en la Universidad de Brasilia. Hasta los docentes se burlaban de nosotros. Recuerdo que uno de ellos dijo, ¿para qué vienen a clase, no prefieren caminar desnudos y vivir en la selva? [...] comencé a organizar a los jóvenes indígenas para luchar contra la discriminación que enfrentábamos todos los días en la universidad (MI PUNTO DE VISTA..., 2017, n. p.).

Cabe aventar que os depoimentos citados referem casos isolados e não a colonialidade que permeia as políticas dessa instituição universitária. Porém, a análise da institucionalização do vestibular específico para indígenas revela um cenário complexo. Após uma década de funcionamento ininterrupto, em 2015 foi suspenso, apesar dos requerimentos formais da AAIUnB. A reabertura ocorreu no início da gestão de Márcia Abrahão (2017-2020), vide figura 1. No entanto, segundo Dirlene Monteiro (Maloca-UnB, 26 abr. 2017), o curso de Medicina não respondeu formalmente e os departamentos de biologia e odontologia negaram a abertura de vagas para discentes indígenas. 
Figura 1: Gestão Universitária 2001-2020. Políticas de ingresso e permanência indígena na UnB.
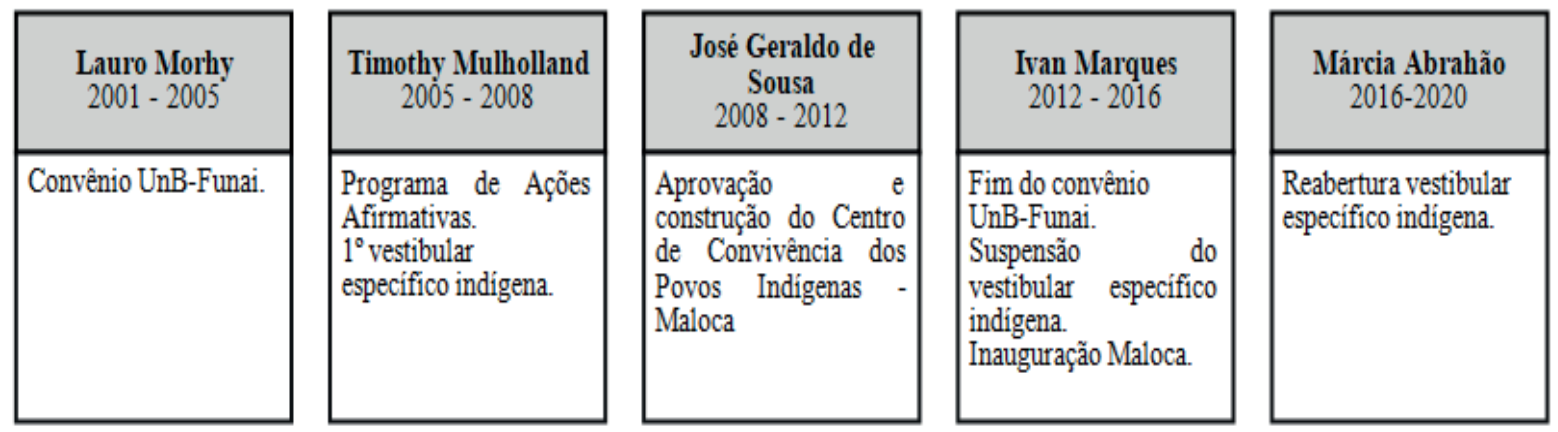

Fonte: elaboração própria.

Essa figura busca enfatizar que o vestibular específico, embora fundamental no âmbito da política de inclusão, não é um instrumento projetado para garantir a permanência de discentes indígenas no ensino superior. Ao contrário, longe de ser uma política pública efetiva, a inclusão por essa única via tem se caracterizado tanto pela intermitência quanto pelo caráter imperecível da vontade política da gestão universitária da UnB, eleita para períodos de quatro anos de duração (OLIVEIRA; RUANO; GUIMARÃES, 2017).

Essa demanda indígena pela abertura de vagas específicas é antiga. Segundo Sousa (2009), o curso de graduação potencializa a emancipação e qualifica as lutas pela garantia de direitos. Segundo Braulina Aurora, a estudante buscou a universidade "com o objetivo de pensar em estratégias para que nós não percamos nossos direitos" (FAGUNDES, 2018). Mas a dinâmica universitária implica no reconhecimento de concepções eurocêntricas que relegam os saberes ancestrais a lugares hierarquicamente inferiores. Por isso, os estudantes indígenas interpelam pela ampliação, validação e circulação de saberes pautados em epistemologias que transcendam a matriz ocidental. Contudo, trata-se de processos sociais complexos que derivam em embates e tensões.

O caráter coletivo do conhecimento revela-se ao contrastarmos a concepção meritocrática do vestibular tradicional, baseada na ideia do acesso como resultado do esforço individual, e a noção de coletividade mobilizada nas narrativas das mulheres indígenas. Essa compreensão do saber como instância que não é individualizada ou individualizante, mas uma conquista coletiva, permite diferenciar o regime de conhecimento indígena que o pressupõe como necessariamente compartilhado e, nesse sentido, coletivo. E, de outro lado, o regime de conhecimento ocidental fundamentado na noção de "indivíduo", de subjetividade particular e do mérito de indivíduos singulares. Desse modo, a vulnerabilidade indígena também é epistêmica. 
Nós viemos questionar. Nossa educação indígena é potente e precisa ser levada a sério. Questionamos a violência contra as mulheres que tomou força com a miscigenação que não foi pacífica, foi violenta. Começou nos corpos das mulheres indígenas e negras que foram estupradas e violentadas. Precisamos falar de feminicídio [...] precisamos avançar e falar de etnofeminicídio, a partir da identidade atrelada aos corpos das mulheres indígenas [...] A política de Ações Afirmativas não dá conta desse território. Porque não é apenas garantir a permanência, é preciso garantir uma política de boa convivência, além da questão financeira. A universidade precisa repensar o acolhimento de alunas indígenas (Célia Nunes Correa, Brasília, 27 mar. 2018).

A noção do corpo feminino como território político foi abordada por Dorotéa Gómez (2014), indígena feminista guatemalteca, para afirmar a dimensão histórica em detrimento do caráter biologizante. Esse posicionamento conceitual e político rejeita as opressões e a alienação, e afiança as memórias, os conhecimentos e as experiências coletivas e pessoais. Habitar o corpo-território desdobra-se em tessituras entre as dimensões emocional, espiritual e racional ao passo em que se renuncia aos mandados patriarcais, racistas e heterossexuais. Portanto, apoiar a reflexão no conceito de corpo-território implicaria em conectar-se política e territorialmente com essas agendas femininas.

Segundo Lorena Cabnal (2010), indígena Maya-Xinca guatemalteca, o corpo-território refere-se à impossibilidade de viver a plenitude da vida enquanto mulheres separadas da terra. Extrapolando o sentido de delimitação geográfica, de acumulação capitalista ou de propriedade privada, vê-se a terra como vínculo, como elemento que relaciona o sujeito individual/coletivo ao cosmos. Assim, corpo e território operam como dimensões indissociáveis ${ }^{1}$. Nesse sentido, Sandra Benites (2018, p. 70) afirma que os corpos e "os jeitos" de ser mulher constituem territórios identitários, relacionando-se às suas especificidades e diferenças enquanto femininos indígenas.

\section{CONCLUSÕES}

O ponto de partida deste trabalho é constituído pela premissa da importância das narrativas femininas indígenas no escopo do pensamento indígena brasileiro. Ao propor questionar a natureza dos empecilhos enfrentados por mulheres e homens indígenas, avançamos na análise

1 Embora a etnologia indígena tenha produzido importante acervo bibliográfico sobre as noções de corpo e território, Lorena Cabnal acunhou essa junção conceitual para legitimar a agenda feminina indígena de denúncia da violência sexual na Guatemala. 
das especificidades da luta indígena pelo direito à educação no Brasil. Aceitando a premissa de Rita Segato (2012) de que a colonialidade atravessa a organicidade dos Estados nacionais, sociedades e povos indígenas, o acesso das mulheres indígenas à universidade sinaliza mudanças nas aldeias de origem e na cena universitária. Suas trajetórias vislumbram a superação de barreiras culturais e econômicas e limites estruturais que enfrentam cotidianamente. Além disso, suas vivências evidenciam desdobramentos da interpelação à colonialidade no cotidiano.

O caráter excludente da universidade materializa-se nas práticas pedagógicas e administrativas denunciadas nas narrativas analisadas. Suas vivências na cena universitária revelam experiências sufocantes e o predomínio da discriminação, silenciamento e invisibilização. As reflexões apontam para diversas opressões escamoteadas na legitimidade institucional universitária, mas também acenam para a importância das políticas afirmativas_enquanto campo de disputa. A permanência indígena no ensino superior indica contestação e resistência epistêmica, que se estendem à afirmação territorial, cultural e política no Estado nacional.

Ao analisar a colonialidade de gênero (LUGONES, 2014) nos territórios e organizações indígenas, destaca-se o tensionamento do distanciamento entre os âmbitos doméstico e público. O gênero é colocado como questão política reveladora das ligações entre democracia e vida doméstica. Por exemplo, toda vez que a integridade física das mulheres é sobrepujada, essa vulnerabilidade dos corpos femininos tensiona a efetividade institucional das regras e valores democráticos. Complementarmente, as narrativas revelam que as barreiras culturais reverberam diferenciadamente para as mulheres indígenas. Nesse caso, as justificativas domésticas acionadas para desencorajar o acesso à universidade ou a participar da cena pública denotam a assimetria feminina na disputa por "direitos constituídos".

Em nossa pesquisa foram tangencialmente abordados os aspectos intra-aldeia, por isso cumpre frisar a importância de que novas pesquisas se debrucem sobre a reconfiguração da ordem tradicional perante o ingresso das novas gerações ao ensino superior. Nessa ordem, torna-se relevante abordar as dinâmicas das aldeias pelo ingresso/vagas na universidade pública, as estratégias coletivas ou individuais para conseguir o apoio formal das lideranças para participar do vestibular específico, o retorno das/dos indígenas após a conclusão, ou não, dos cursos superiores e sobre a aplicação, ou não, dos conhecimentos apropriados. Ao sugerirmos essas temáticas não pretendemos fornecer um levantamento exaustivo, mas referir indagações que julgamos merecerem aprofundamentos futuros.

A defesa do direito à educação e, especificamente, o acesso à universidade constitui uma política de subversão e resistência dos movimentos indígenas, porém, parece ser definidora do reposicionamento das mobilizações femininas na cena pública. Afiançando seus posicionamen- 
tos, as narrativas femininas analisadas veiculam pensamentos sofisticados e transformadores que tratam dos movimentos etno-políticos, da politização das simplificações, silêncios e entrecruzamentos de padrões de desigualdade. Seus depoimentos sugerem que a colonialidade enquanto eixo articulador de discriminações múltiplas fere-as habitualmente, porém, também é cotidiana a resistência ativa das mulheres indígenas.

Se nas mobilizações indígenas da segunda metade do século XX, as assimetrias entre os gêneros se "resolveram", sob a premissa da aceitação da divisão sexual do trabalho, e tal acordo implícito pareceu dar conta da política étnica interna e externa, não parece ser mais o caso das mobilizações do final da segunda década do século XXI. A partir das narrativas indígenas analisadas, onde contamos com mulheres das etnias Tikun, Xavante, Tupinambá, Baré, Ticuna, Potiguara, Guajajara, Xacriabá e Baniwa, tentamos buscar pistas para melhor compreender as dinâmicas em curso. É preciso discutir se de fato houve mudança no agenciamento feminino, ou se mudou a lente da pesquisa social que finalmente nos permite enxergar o silenciamento feminino na política étnica voltada para a esfera externa.

A abordagem sobre o acesso ao ensino superior e as narrativas de mulheres indígenas permitem destacar seu pensamento no campo de lutas e disputas dos movimentos indígenas. Nesse ponto, por meio da atuação em diferentes organizações, estão sendo consolidadas ações direcionadas à visibilidade feminina, bem como das violências específicas que as oprimem. Transgredindo as regras que visam alojá-las no âmbito doméstico, a participação no espaço público corrobora para a mudança de estruturas historicamente demarcadas como masculinas. Nesse sentido, as agendas desses movimentos começaram a incluir demandas de gênero como eixo primordial, somando-se às reivindicações territoriais e educacionais.

Essas narrativas de mulheres indígenas no ensino superior brasileiro defendem a conjugação de conhecimentos para continuar na empreitada de construção da sua autonomia e interpelação de preconceitos e hierarquias nos espaços sociais. A viabilidade da conclusão dos cursos de graduação e pós-graduação pelo estudantado indígena é condicionada ao aprimoramento das políticas de ingresso e permanência. Nesse espectro, bolsas e auxílios tornam-se imprescindíveis, assim como a premente descolonização das práticas políticas, pedagógicas, epistêmicas e de sociabilidade universitária.

\section{REFERÊNCIAS}

1. BARROS, Aparecida. Vestibular e Enem: um debate contemporâneo. Ensaio: aval. pol. 
públ. Educ. (online). Rio de Janeiro, v. 22, n. 85, p. 1057-1090, 2014.

2. BELCHIOR, Ernandes. Não deixando a cor passar em branco: o processo de implementação de cotas para estudantes negros na Universidade de Brasília. 2006. Dissertação (Mestrado em Sociologia) - Universidade de Brasília, Brasília, 137 f.

3. BENITES, Sandra. Viver na língua Guarani Nhandeva (mulher falando). 2018. Dissertação (Mestrado em Antropologia Social) - Programa de Pós-Graduação em Antropologia Social, Museu Nacional, Universidade Federal do Rio de Janeiro, Rio de Janeiro.

4. BÓ, Talita Lazarin Dal'. A presença de estudantes indígenas nas universidades: entre ações afirmativas e composições de modos de conhecer. 2018. Tese (Doutorado em Antropologia Social) - Faculdade de Filosofia, Letras e Ciências Humanas, Universidade de São Paulo, São Paulo.

5. CABNAL, Lorena. Acercamiento a la construcción de la propuesta de pensamiento epistémico de las mujeres indígenas feministas comunitarias de Abya Yala. In: CABNAL, Lorena. Feminismos diversos: el feminismo comunitario. Las Segovias: Asociación para la cooperación con el Sur, ACSUR, 2010, p. 11-25.

6. COHN, Sérgio; KADIWEL, Idjahue. Sônia Guajajara. Rio de Janeiro: Tembeta. 2018, $117 \mathrm{p}$.

7. CORREA, Célia Nunes. O barro, o genipapo e o giz no fazer epistemológico de autoria xakriabá: Reativação da memória por uma educação territorializada. 2018. Dissertação (Mestrado em Sustentabilidade junto a Povos e Terras Tradicionais) - Centro de Desenvolvimento Sustentável, Universidade de Brasília. $128 \mathrm{f}$.

8. CRUZ, Felipe. Indígenas antropólogos e o espetáculo da alteridade. Revista de Estudos e Pesquisas sobre as Américas, v. 11, n. 2, 2016. Disponível em: https://periodicos.unb. br/index.php/repam/article/view/15949. Acesso em: 18 mar. 2018.

9. CUMES, Aura Estela. Mujeres indígenas patriarcado y colonialismo: un desafío a la segregación comprensiva de las formas de dominio. Anuário hojas de Warmi. n. 17, p. 1-16, 2012. Disponível em: https://revistas.um.es/hojasdewarmi/article/view/180291. Acesso em: 18 mar. 2020.

10. FAGUNDES, Murilo. Dia do Índio: indígenas reforçam luta contra preconceito e estereótipos. Correio Braziliense, 2018. Disponível em: https://www.correiobraziliense. com.br/app/noticia/cidades/2018/04/19/interna_cidadesdf,674715/dia-do-indioindigenas-reforcam-luta-contra-preconceito-e-estereotipo.shtml. Acesso em: 19 abr. 2018 .

11. GARGALlO, Francesca. Feminismos desde Abya Yala. Ideas y proposiciones de las mujeres de 607 pueblos en nuestra América. México: Corte y Confección, 2014.

12. GÓMEZ, Dorotéa. Mi cuerpo es un territorio político. In: MIÑOSO, Yuderkys; 
CORREAL, Diana; MUÑOZ, Karina. (Ed.). Tejiendo de otro modo. Feminismo, epistemología y apuestas descoloniales en Abya Yala. Popayán: Universidad del Cauca, 2014, p. 263-276.

13. GUEDES, Moema de Castro. A presença feminina nos cursos universitários e nas pósgraduações: desconstruindo a ideia da universidade como espaço masculino. História, Ciências, Saúde - Manguinhos, Rio de Janeiro, v.15, p.117-132, jun. 2008. Disponível em: https://www.redalyc.org/pdf/3861/386138040006.pdf. Acesso em: 03 mar. 2018.

14. LUCIANO, Gersem. Educação para manejo e domesticação do mundo entre a escola ideal e a escola real: os dilemas da educação escolar indígena no Alto Rio Negro. 2011. Tese (Doutorado em Antropologia) - Universidade de Brasília, Brasília.

15. LUGONES, María. Rumo a um feminismo descolonial. Revista Estudos Feministas. v. 22, n. 3, p. 935-952, 2014. Disponível em: https://periodicos.ufsc.br/index.php/ref/ article/view/36755. Acesso em: 03 mar. 2018.

16. MATOS, Maria Helena Ortolan. Mulheres no movimento indígena: do espaço de complementariedade ao lugar da especificidade. In: SACCHI, Ângela; GRAMKOW, Márcia Maria (Org.). Gênero e povos indígenas. Coletânea de textos produzidos para o "Fazendo Gênero 9" e para a "27 Reunião Brasileira de Antropologia". Rio de Janeiro; Brasília: Museu do Índio/GIZ/FUNAI, 2012.

17. MENENDEZ, Larissa. Literatura indígena, memória e resistência: A Casa-universo na obra de Gabriel Gentil e Luís Lana. Polifonía. v. 21, n. 30, p.133-150, 2014. Disponível em: https://periodicoscientificos.ufmt.br/ojs/index.php/polifonia/article/ view/1355/1653. Acesso em: 03 mar. 2018.

18. MI PADRE ME DIJO "quiero que un día puedas contribuir a tu pueblo". ONU Mujeres, 2014. Disponível em: https://www.unwomen.org/es/news/stories/2014/3/i-want-you-tobe-able-to-help-your-people-one-day. Acesso em: 03 mar. 2018.

19. MI PUNTO DE VISTA: "Es hora de que el mundo escuche nuestra voz". ONU Mujeres, 2017. Disponível em: https://lac.unwomen.org/es/noticias-y-eventos/articulos/2017/08/ desde-mi-perspectiva-rayanne-cristine-maximo-franca. Acesso em: 18 mar. 2018.

20. MORA, Paulina. Género, Inclusión y Educación Superior. In: VAREA, Soledad; ZARAGOCIN, Sofia (Ed.). Feminismo y buen vivir: utopías decoloniais. Cuenca: Pidlos, 2017, p. 134-145.

21. OLIVEIRA, Victoria; RUANO, Elizabeth; GUIMARÃES, Silvia. Ensino superior brasileiro e povos indígenas: os desafios da diversidade étnica na universidade de Brasília. In: DOMINGUEZ, Carlos. Direitos humanos e cidadania no Brasil: estudos interdisciplinares. Curitiba: CRV, 2017, p. 175-198.

22. PAREDES, Julieta. El feminismo comunitario: la creación de un pensamiento propio. Revista Corpus. v. 7, n. 1, p. 1-10, 2017. Disponível em: https://journals.openedition. org/corpusarchivos/1835. Acesso em: 03 mar. 2018. 
23. PASCOAL, Walison. Os sentidos de luta e a "ressurgência cultural" entre os Krenak. Interethnic@.v. 20, n. 2, p. 87-108, 2017. Disponível em: https://periodicos.unb.br/ index.php/interethnica/article/view/10619. Acesso em: 02 mar. 2018.

24. PEARCE, Diane. The feminization of poverty: women, work and welfare. Urban and Social Change Review. v. 11, n. 1-2, p.28-36, 1978.

25. PERES, Julie. Literatura indígena e seus intelectuais no Brasil: da autoafirmação e auto expressão como minoria à resistência e à luta político-culturais. Revista de estudos e pesquisas sobre as Américas. v. 11, n. 3, p. 114-136, 2017. Disponível em: https:// periodicos.unb.br/index.php/repam/article/view/15969. Acesso em: 02 mar. 2018.

26. RIBEIRO, Maria Fernanda. "Ser indígena hoje é sinônimo de resistência", diz Nara Baré, a primeira mulher a assumir a Coiab. Amazônia Real. Disponível em: https:// amazoniareal.com.br/ser-indigena-hoje-e-sinonimo-de-resistencia-diz-nara-bareprimeira-mulher-assumir-coiab/. Acesso em: 15 abr. 2019.

27. ROSSI, Marina. "Dizer que nós mulheres indígenas não enfrentamos violência de gênero é mentira". El País, 2019. Disponível em: https://brasil.elpais.com/brasil/2019/04/26/ politica/1556294406_680039.html. Acesso em: 29 abr. 2019.

28. RUANO, Elizabeth; SOUZA, Liliana. Mulheres Ticuna: gênero e política na Amazônia. Amazônica-Revista de Antropologia. v. 8, n. 1, p. 90-117, 2017. Disponível em: https:// periodicos.ufpa.br/index.php/amazonica/article/view/4726. Acesso em: 20 mar. 2018.

29. SANTOS, Eliane. Metade cara, metade máscara. São Paulo: Global. 2004.

30. SANTOS, Tânia. Experiência de escrita e reescrita de textos em português por alunos indígenas da licenciatura intercultural da UFG. In: MENDES, Leandro Rocha; PIMENTEL, Maria Silva; BORGES, Mônica Veloso. Cidadania, interculturalidade e formação de docentes indígenas. Goiânia: Ed. da PUC, 2010, p. 119-132.

31. SCARPIN, Paula. A experiência de dez anos de convênio entre a Universidade de Brasília e a Funai. Revista Piauí, 2013. Disponível em: https://piaui.folha.uol.com.br/ materia/laboratorio-indigena/. Acesso em: 18 fev. 2017.

32. SEGATO, Rita Laura. Gênero e colonialidade: em busca de chaves de leitura e de um vocabulário estratégico descolonial. E-cadernos CES. n. 18, p. 106-131, 2012. Disponível em: https://journals.openedition.org/eces/1533. Acesso em: 18 fev. 2018.

33. SOUSA, Josicélia. Os desafios dos estudantes e das instituições no convênio. 2009. Trabalho de Conclusão de Curso (Especialização) - Fundação Nacional do Índio, Universidade de Brasília, Brasília, 2009.

34. INDÍGENAS de 15 diferentes povos integram comunidade acadêmica da UnB. UnB Notícias, 2017. Disponível em: https://www.noticias.unb.br/publicacoes/67ensino/1697-indigenas-de-15-diferentes-povos-integram-comunidade-academica-daunb. Acesso em: 15 jul. 2019. 
35. WELLER, Wivian. Diferenças e desigualdades na Universidade de Brasília: experiências de jovens negras e suas visões sobre o sistema de cotas. Revista Política e Sociedade, v. 6, n. 11, p. 133-158, 2007. Disponível em: https://periodicos.ufsc.br/index.php/politica/ article/view/1264. Acesso em: 19 jul. 2019.

\section{Elizabeth del Socorro Ruano-Ibarra}

Doutora em Ciências Sociais. Professora visitante do Departamento de Estudos Latino-americanos na Universidade de Brasília. Docente Permanente do Programa de Pós-Graduação em Ciências Sociais - Estudos Comparados sobre as Américas. Pesquisadora do Laboratório de Estudos e Pesquisas sobre Movimentos Indígenas, Políticas Indigenistas e Indigenismo. Pesquisadora do Grupo de Investigación Interdisciplinar en Ciencias Humanas. ID ORCID: http://orcid.org/0000-0003-0549-3951. E-mail: elizabeth@unb.br. Colaboração: Pesquisa bibliográfica; Pesquisa empírica; Análise de dados; Redação; Revisão.

Victoria Miranda da Gama Oliveira

Bacharel em Antropologia pela Universidade de Brasília. Graduanda do Departamento de Direito da Universidade de Brasília. Pesquisadora do Laboratório de Estudos e Pesquisas sobre Movimentos Indígenas, Políticas Indigenistas e Indigenismo. ID ORCID: https://orcid.org/0000-0003-3446-0817. E-mail: vicmgama@gmail.com. Colaboração: Pesquisa bibliográfica; Pesquisa empírica; Análise de dados; Redação; Revisão. 